\title{
AMMI Analysis for Grain Yield Stability in Lentil Genotypes Tested in the Highlands of Bale, Southeastern Ethiopia
}

\author{
Tadele Tadesse ${ }^{1, ~}$, Gashaw Sefera ${ }^{2}$, Belay Asmare ${ }^{1}$, Amanuel Tekalign ${ }^{1}$ \\ ${ }^{1}$ Sinana Agriculture Research Center, Bale-Robe, Ethiopia \\ ${ }^{2}$ Fiche Agriculture Research Center, Fiche, Ethiopia
}

Email address:

tadyeko20@gmail.com (T. Tadesse), tadeleta20@yahoo.com (T. Tadesse)

*Corresponding author

\section{To cite this article:}

Tadele Tadesse, Gashaw Sefera, Belay Asmare, Amanuel Tekalign. AMMI Analysis for Grain Yield Stability in Lentil Genotypes Tested in the Highlands of Bale, Southeastern Ethiopia. Journal of Plant Sciences. Vol. 9, No. 1, 2021, pp. 9-12. doi: 10.11648/j.jps.20210901.12

Received: December 30, 2020; Accepted: January 15, 2021; Published: January 30, 2021

\begin{abstract}
Lentil (Lens culinaris Medik.) as grain legumes it ranks seventh and it is a valuable source of dietary protein. Genotype $\mathrm{x}$ environment interaction is the main determinant in identifying genotypes with wider adaptation. A total of seventeen lentil genotypes was used in this study, where the evaluation was made at Sinana and Agarfa for three years 20162018. In this study it was revealed that significant variation among the genotypes, locations and genotypes by location interaction for mean grain yield was observed It is also observed in the AMMI analysis significant variation in the first two IPCA components. Accordingly, G1, G6, G13, G14, G16 and G17 gave grain yield above the grand mean. Furthermore, from the stability indicators like AMMI Stability Value: G4, G15 G8, G6, G10, had lower ASV value and showed stabile performance while G7, G11 and G1 had relatively lower ASV and showed moderately stable performance over the testing environments indicating wide adaptation. Furthermore, based on the Genotypes Selection Index (GSI) the most stable genotypes with a high grain yield were G1 and G15. Therefore, we have identified that these two genotypes as candidate genotypes to be verified for possible release in the highlands of bale, Sothern Ethiopia and similar agro-ecologies.
\end{abstract}

Keywords: AMMI Stability Value, GE interaction, Genotype Selection Index, Stability

\section{Introduction}

Lentil one of the important food legume crops having diploid $(2 \mathrm{n}=2 \mathrm{x}=14$ chromosomes). It ranks fourth in the world. In human diets, since it has up to $28 \%$ protein, it is highly preferred in many parts of the world, like west Asia $[10,16]$. Unless improved varieties of lentil along with their full packages of production is used, the production obtained from most cultivars is below the national average [5]. Since yield is governed by many complex traits, for breeders it is very difficult to get genotypes for high mean yield and yield stability. Having of cultivars that perform in similar fashion over all the testing environments with stable manner is very important for the farmers in order to boost their production with needed quantity and quality. [7]. Like other crops, in lentil also identifying stable genotypes is the final goal.. Genotypic main effect $(G)$, environmental main effect $(E)$ and their interaction are the factors that determine the performance of the genotype [17]. To determine stability in lentil genotype, having knowledge on the genotype by environment (GE) interactions is necessary for the breeder to make effective selection of genotypes [15]. Thus, the GE interactions structure is played great role for the both the breeding program and for identification of stablity in crop improvement [13].

When a genotypes has similar performance when grown over wide environments, the genotypes are considered as stable [2]. Though there are various methods for the analysis of multi-location trials, AMMI is the most preferred one since it used to partitioned the interaction sum of square to the existing source of variation [9]. Furthermore, AMMI is useful in grouping the mega-environment into similar small regions having the same patterns which helps to recommend cultivars [18]. Therefore, this study was initiated to asses genotypes that have high yield with wider adaptation. 


\section{Materials and Methods}

\subsection{Testing Sites al Locations}

The experiment was carried out at two locations, Sinana and Agarfa, representing potential production sites for lentil. The experiment was conducted at each location on vertisol clay loam soil under rain fed conditions during the meher season (August-January) of 2016 to 2018 cropping season. Fifteen lentil genotypes along with one standard check, Asano, and local cultivar were tested to see their wide adaptability across the testing sites. The genotypes were laid out using randomized complete block design with four replications. The plot size used was $3.2 \mathrm{~m}^{2}$.

\subsection{Analysis of Variance}

ANOVA was calculated using CROPSTAT ver 7.2 program. Furthermore, AMMI analysis was analyzed using the model suggested as $Y_{i j}=\mu+g_{i}+e_{j}+\sum_{n=1}{ }^{h} \lambda_{n} \alpha_{n i} . Y_{n j}+R_{i j}[3]$.

Where, $Y_{i j}$ is the yield of the $i^{\text {th }}$ genotype in the $j^{\text {th }}$ environment, $\mu$ is the grand mean, $g_{i}$ is the mean of the $i^{\text {th }}$ genotype minus the grand mean $e_{j}$ is the mean of $j^{\text {th }}$ environment minus the grand mean, $\lambda_{n}$ is the square root of the eigen value of the principal component Analysis (PCA) axis, $\alpha_{n i}$ and $Y_{n j}$ are the principal and the principal component scores for the PCA axis $n$ of the $i^{\text {th }}$ genotype and $j^{\text {th }}$ environment, respectively and $\mathrm{R}_{\mathrm{ij}}$ is the residual. The ASV is the distance from the coordinate point to the origin in a two dimensional of IPCA1 score against IPCA2 scores in the AMMI model was calculated by the model suggested as

$$
\mathrm{ASV}=\sqrt{\left[\frac{\text { SSIPCA1 }}{\operatorname{SSIPCA2}(I P C A 1 \text { score })]^{2}+[I P C A 2\rceil^{2}}\right.}
$$

[14].

\subsection{Stability Analysis}

Where, $\frac{S S I P C A 1}{S S I P C A 2}$, the weight given to the IPCA1 value by dividing the IPCA1 sum squares by the IPCA2 sum of squares.

Genotype Selection Index (GSI): was calculated by the methods suggested as

$$
\mathrm{GSI}_{\mathrm{i}}=\mathrm{RY}_{\mathrm{i}}+\mathrm{RASV}_{\mathrm{i}}[6]
$$

\section{Result and Discussion}

\subsection{Analysis of Variance}

The combined Analysis of Variance (Table 2) revealed that significant variation among genotypes, locations and GE interaction for mean grain yield of lentil. A similar result of significant variation of genotypes and genotypes by environment interaction was reported by [11]. Furthermore, they have explained that the significances variation among the environments indicate that as the locations were very diverse while significant differences among genotypes reveals the differential response of genotypes to different environments.. The percentage for total variation from the total sum of square (SS) of grain yield by environment is $29.65 \%$, for genotype $8.11 \%$ and it was $4.42 \%$ for the genotype $\mathrm{x}$ environment (Table 2).

The largely yield variation, explained by environments, indicated that the environments were diverse and a major part of variation in grain yield can be resulted from environmental changes. The same result was reported by $[1,11]$.

Table 1. Genotype code and the name of 17 lentil genotypes.

\begin{tabular}{lll}
\hline No. & Genotype code & Name \\
\hline 1 & G1 & DZ -2012-LN-0085 \\
2 & G2 & DZ -2012-LN-0057 \\
3 & G3 & DZ -2012-LN-0059 \\
4 & G4 & DZ -2012-LN-00118 \\
5 & G5 & FLIP-96-49L \\
6 & G6 & DZ -2012-LN-0038 \\
7 & G7 & DZ -2012-LN-00107 \\
8 & G8 & DZ -2012-LN-0048 \\
9 & G9 & FLIP-97-33L \\
10 & G10 & DZ -2012-LN-0065 \\
11 & G11 & FLIP-86-38L \\
12 & G12 & FLIP-89-19L \\
13 & G13 & DZ -2012-LN-0095 \\
14 & G14 & DZ -2012-LN-0051 \\
15 & G15 & Asano \\
16 & G16 & Local check \\
17 & G17 &
\end{tabular}

\subsection{AMMI Analysis}

The AMMI analysis of variance showed highly significant differences for the main and interaction effects. Table 3 explained AMMI analysis.

Table 2. The combined ANOVA for grain yield of lentil over locations and years.

\begin{tabular}{lllll}
\hline $\begin{array}{l}\text { Source of } \\
\text { Variation }\end{array}$ & $\begin{array}{l}\text { Degree } \\
\text { freedom }\end{array}$ & $\begin{array}{l}\text { Sum } \\
\text { Squares }\end{array}$ & $\begin{array}{l}\text { Mean } \\
\text { Squares }\end{array}$ & $\begin{array}{l}\text { \% explained } \\
\text { of TSS }\end{array}$ \\
\hline YEAR (Y) & 2 & 42.5821 & 21.291 & 15.68 \\
Location (L) & 1 & 80.5456 & 80.5456 & 29.65 \\
Replication & 3 & 0.260409 & 0.0868 & 0.10 \\
Genotype (G) & 16 & 22.0293 & 1.37683 & 8.11 \\
Y X L & 2 & 44.0381 & 22.019 & 16.21 \\
G X E & 16 & 12.0086 & 0.750539 & 4.42 \\
Y X L X G & 64 & 31.642 & 0.494406 & 11.65 \\
RESIDUAL & 303 & 38.5488 & 0.127224 & 14.19 \\
TOTAL & 407 & 271.655 & 0.667457 & \\
\hline
\end{tabular}

Table 3. Analysis of Variance for grain yield of lentil for the AMMI model.

\begin{tabular}{lllll}
\hline Sources & DF. & SS & MS & $\begin{array}{l}\text { TSS } \\
\text { explained \% }\end{array}$ \\
\hline Genotypes & 16 & 5.50732 & $0.344207 * *$ & 9.46 \\
Environment & 5 & 41.7914 & $8.35829 * *$ & 71.79 \\
G X E & 80 & 10.9126 & $0.136408 * *$ & 18.75 \\
AMMI COMPONENT 1 & 20 & 5.07988 & $0.253994 * *$ & 46.55 \\
AMMI COMPONENT 2 & 18 & 3.75266 & $0.208481 * *$ & 34.39 \\
AMMI COMPONENT 3 & 16 & 1.3651 & $0.085319 * *$ & 12.51 \\
AMMI COMPONENT 4 & 14 & 0.434769 & $0.031055^{* *}$ & 3.98 \\
GXE RESIDUAL & 12 & 0.28024 & & \\
TOTAL & 101 & 58.2114 & & \\
\hline
\end{tabular}

It is indicated in Table 3 that of the total variation observe in grain yield accounted for environment was $71.79 \%$ whereas 
$9.46 \%$ and $18.75 \%$ of the variation was accounted for genotypes and genotypes by environment interaction, respectively. The AMMI model partitioned among the first two IPCA. Of the total GEI variation observed, about $46.55 \%$ was accounted for AMMI1 whereas $34.39 \%$ was accounted by AMMI2 (Table 3). Since the first two AMMI components in total accounted for $80.94 \%$ of the variation, It was also reported as the first two interaction principal component axis best predictive model explain the interaction sum of squares by $[3,18]$.

\subsection{Stability Analysis by AMMI Model}

AMMI Stability Value (ASV): [14] indicated as the distance from the coordinate point to the origin in a two dimensional scatter gram of the two IPCA1 scores. The ASV and other stability parameters values along with the mean yield of the genotype are presented in Table 4. The highest mean grain yield of genotypes averaged over environments was obtained from DZ -2012-LN-0085 (2.31 $\left.\mathrm{tha}^{-1}\right)$ followed by DZ -2012-LN-0051 (2.06t ha $\left.{ }^{-1}\right)$ and DZ -2012-LN-0095 $\left(1.98 \mathrm{tha}^{-1}\right)$. The genotypes with low stability value (ASV) is said to be stable and the breeder chose the stable genotypes, having grain yield above the mean grand yield. In this study genotype G4 showed lowest ASV followed by G5, G8, G6, and G10 (Table 4) indicating these genotypes have stable performance over the studied environments.

Table 4. Mean yield, First and second IPCA and various yield-stability statistics investigated in lentil.

\begin{tabular}{|c|c|c|c|c|c|c|c|c|c|}
\hline Trt Code & Mean & Rank Yi & Slope (bi) & MS-DEV (S ${ }^{2}$ di) & IPCA1 & IPCA2 & ASV & Rank ASV & GSI \\
\hline G1 & 2.31 & 1 & 0.86 & 0.07 & 0.15 & -0.35 & 0.43 & 8 & 9 \\
\hline G2 & 1.70 & 11 & 1.30 & 0.31 & -0.42 & 0.73 & 1.01 & 15 & 26 \\
\hline G3 & 1.54 & 15 & 1.48 & 0.12 & -0.58 & -0.15 & 0.97 & 14 & 29 \\
\hline G5 & 1.82 & 10 & 1.14 & 0.06 & -0.24 & -0.21 & 0.45 & 9 & 19 \\
\hline G6 & 1.88 & 6 & 1.03 & 0.06 & 0.03 & -0.24 & 0.24 & 4 & 10 \\
\hline G7 & 1.85 & 7 & 1.15 & 0.10 & -0.11 & -0.30 & 0.35 & 6 & 13 \\
\hline G9 & 1.85 & 7 & 1.36 & 0.02 & -0.39 & 0.02 & 0.64 & 12 & 19 \\
\hline G10 & 1.85 & 7 & 1.02 & 0.05 & -0.02 & 0.29 & 0.29 & 5 & 12 \\
\hline G11 & 1.64 & 12 & 1.22 & 0.05 & -0.18 & -0.20 & 0.36 & 7 & 19 \\
\hline G12 & 1.96 & 4 & 1.25 & 0.11 & -0.27 & -0.36 & 0.57 & 11 & 15 \\
\hline G13 & 1.59 & 13 & 0.68 & 0.11 & 0.44 & 0.30 & 0.78 & 13 & 26 \\
\hline G14 & 1.98 & 3 & 0.85 & 0.11 & 0.29 & 0.18 & 0.51 & 10 & 13 \\
\hline G15 & 2.06 & 2 & 1.00 & 0.02 & -0.09 & -0.08 & 0.17 & 2 & 4 \\
\hline G16 & 1.59 & 13 & 0.39 & 0.13 & 0.65 & 0.47 & 1.17 & 16 & 29 \\
\hline
\end{tabular}

Most of the time stable genotypes don't give higher yield [12], hence, Genotype Selection Index should which consider the mean grain yield and ASV should be considered to determine the stability of the genotypes. Accordingly, G4, G15, G1 and G6 had the lowest GSI values compared to the other genotypes and showed stable performance over the testing sites. Therefore, G1 and G15 were the stable and high yielder genotypes across the testing environments.

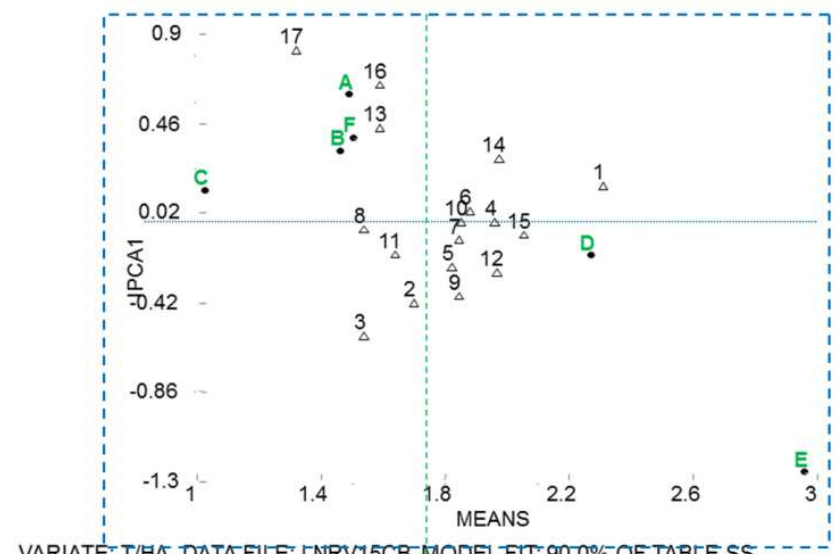

VARIATE: T/AA DATAFILE: LNRV15CB MIODEL FIT: 90.0\% OF TABLE SS - - -

Figure 1. Biplot analysis of GEI based on AMMI 1 model for the PCAI scores and grain yield.

\section{INTERACTION BIPLOT FOR THE AMMI2 MODEL}

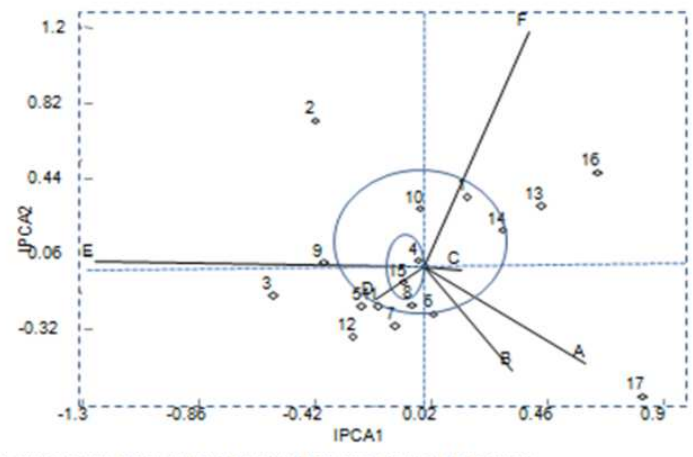

VARIATE: T/HA DATA FILE: LNRV15CB MODEL FIT: $80.9 \%$ OF GXE SS

Figure 2. Interaction biplot for the AMMI model.

\subsection{AMMI 1 Biplot}

Biplots are graphs where both genotypes and environments are plotted on the same axes so that interrelationships can be visualized. The two AMMI biplots were constructed by the use of IPCA components and mean grain yield. In the AMMI 1 biplot, genotypes that founds in the same quadrants showes similar adaptation similarly environments also influence genotypes when the grouped under the same quadrants [8]. In the present study, G9, G7, G5, G10, G6, G4, G12, G4, G14, G15, and G1 gave a higher grain yield than the mean value 
(Figure 1). This indicated that these genotypes are less affected by GxE interaction.

\subsection{AMMI 2 Biplot}

Biplots can help to display GE interactionbwhen the intraction is partitioned in to two interaction pricipal component axis. These two IPCA determines the superiority of the genotypes to create a two dimensional GGE biplot. Genotypes found closet to the ordinate showed wider adaptation and those found far away from the ordinates depicted narrow adaptation [4]. Arrows used to connect the Environments. The genotypes which are found at near distance to the origin showed wider adaptation than those found at far distance away from the origin $[4,8]$. According to the present study, G4, G15 and G8 are the most stable genotypes and showed wider adaptation over the studied environments, whereas G6, G10, G1, and G14 showed moderately stable performance. Therefore, from the stability points of view, when both stability parameters and mean grain yield are considered in order to identify best stable and high yielder lentil genotypes, G1 and G15 were the best genotypes. Furthermore, these two genotypes have tolerant types of interaction for the majority of the diseases scores observed during the growing period (Table 3). Therefore, we have identified as candidate genotypes, and recommended to be verified for possible release for the highlands of bale zone and similar agro-ecologies.

\section{Conclusion}

Crop yield is influenced by a number of characters along with the environments since it is a complex trait. AMMI is powerful tool to identify stable and high yielding genotypes for specific and broaden sense of adaptability. In the present study, the greatest variation from the total differences observed in grain yield as clearly noted by AMMI model. It is conclude that from the total genotypes tested, genotypes G1 and G15 because of their higher yield and showed stable performances over the testing environments with yield advantage of $45.28 \%$ and $29.56 \%$ over the standard check, Asano (1.59t/ha). they were identified as candidate genotypes, and recommended to be verified in the coming cropping season for possible release in the highlands of bale and similar agro-ecologies.

\section{Acknowledgements}

We would like to thank Oromia Agricultural Research Institute for funding, and Sinana Agriculture Research Center and pulse and oil crops research case team for full support, data collection and trial management.

\section{References}

[1] Akter, A., Jamil Hassan, M., Umma Kulsum, M., Islam, M. R., Hossain, K.(2014) AMMI Biplot Analysis for Stability of Grain Yield in Hybrid Rice (Oryza sativa) analysis of genotype-by-environment data. Crop Sci., 47: 643-655.
[2] Arshad, M., Bakhsh, A., Haqqani, A. M., Bashir, M. (2003) Genotype - environment interaction for grain yield in chickpea (Cicer arietinum L.). Pak. J. Bot. 35 (2): 181-186.

[3] Crossa, J., Fox P. N., Pfeiffer, W. H., Rajaram, S., and Gauch, H. G. 1991 AMMI adjustment for statistical analysis of an interactional wheat yield trial. Theor. App Gent, 81: 27-37.

[4] Ebdon, J., and Gauch, H. 2002. Additive Main Effect and Multiplicative Interaction Analysis of National Turfgrass Performance Trials. I. Interpretation of Genotype $\times$ Environment Interaction. Crop Sci., 42 (2): 489-496.

[5] Erskine, W. Global production, supply and demand // The lentil: botany, production and uses / Erskine W. et al. (eds). UK, 2009, p. 4-13.

[6] Farshadfar, E. 2008. Incorporation of AMMI stability value and grain yield in a single non-parametric index (GSI) in bread wheat. Pak J Biol Sci, 11 (4): 1791-1796.

[7] Gauch, H. G., Piepho, H. P., Annicchiaricoc, P. 2008. Statistical analysis of yield trials by AMMI and GGE. Further considerations // Crop Science. vol. 48, p. 866-889.

[8] Gauch, H. G., Zobel, RW., Kang, M. S., and Gauch, H. G. 1996. AMMI analysis of yield trials. Genotype byenvironment interaction, pp: 85-122. Gujarat Agric Uni Res J. 22: 101-102.

[9] Gauch, H. G., 1992. Statistical Analysis of Regional Yield Trials: AMMI Analysis of Factorial Designs. Elsevier, Netherlands, Amsterdam.

[10] Gauch, H. G., 1982. Multivariate analysis in community ecology. Cambridge Univ. Press, London and New York.

[11] Karimizadeh.., and M. Mohammadi, 2010. AMMI adjustment for rain fed lentil yield trials in Iran. Bulg. J. Agric. Sci., 16: 66-73.

[12] Mohammadi, R., Abdulahi, A., Haghparast, R., and Armion M. 2007. Interpreting genotype environment interactions for durum wheat grain yields using non-parametric methods. Euphytica. 157: 239-251.

[13] Neacşu, A. 2001. Grain protein concentration and its stability in a set of winter wheat cultivars, grown in diverse environments and management practices // Romanian Agricultural Research. vol. 28, p. 29-36.

[14] Purchase, J. L., Hatting H., and Vandenventer, C. S. 2000. Genotype $\mathrm{x}$ environment interaction of winter wheat in south Africa: II. Stability analysis of yield performance. South Afr J Plant Soil, 17: 101-107.

[15] Sabaghnia, N., Sabaghpour, S. H., Dehghani, H. 2008. The use of an AMMI model and its parameters to analyse yield stability in multi-environment trials // Journal of Agriculture Science. vol. 146, p. 571-581.

[16] Sarker, A., Erskine, W., and Singh, M. 2003. Regression models for lentil seed and straw yields in Near East. Agricultural and Forest Meteorology, 116: 61-72.

[17] Yan, W., Kang, M. S., Ma B., Wood, S., and Cornelius, P. L. 2007. GGE biplot vs. AMMI analysis of genotype-byenvironment data // Crop Science. vol. 47, p. 643-655.

[18] Zobel, R. W., and H. G., Gauch, 1988. Statistical analysis of a yield trial. Agron. J., 80: 388-393. 